\title{
Qing-dai powder promotes recovery of colitis by inhibiting inflammatory responses of colonic macrophages in dextran sulfate sodium-treated mice
}

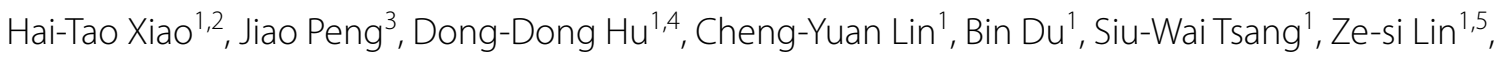 \\ Xiao-Jun Zhang ${ }^{1,6}$, Feng-Ping Lueng ${ }^{1}$, Quan-Bin Han $^{1}$ and Zhao-Xiang Bian ${ }^{1 *}$
}

\begin{abstract}
Background: Qing-dai powder (QDP), comprising Indigo naturalis (Qing-dai) and dried alum (Ku-fan), was used in Chinese medicine to treat the conditions associated with mucosal hemorrhage, such as ulcerative colitis (UC). This study aims to investigate the effects and potential mechanism of QDP on dextran sulfate sodium (DSS)-induced acute colitis in mice and to examine the regulatory effects of QDP on macrophages.

Methods: Seven- to eight-week-old male C57BL/6 mice were challenged with $2.0 \%$ DSS in drinking water for 5 days and then the colitic mice were arbitrarily allocated into five groups ( $n=10$ for each group). QDP $(0.77,1.54$ and $3.08 \mathrm{~g} / \mathrm{kg}$ ) and sulfasalazine (SASP) $(0.20 \mathrm{~g} / \mathrm{kg})$ were orally administered for 7 days. The disease activity index was determined by scores of body weight loss, diarrhea and rectal bleeding; histological signs of damage was analyzed by H\&E staining; myeloperoxidase activity was measured by colorimetric method, levels of proinflammatory cytokines were determined by ELISA; changes in macrophages in the colon were analyzed by immunohistochemistry $(\mathrm{IHC})$ and flow cytometry. Lipopolysaccharide (LPS)-induced RAW264.7 cells were treated with or without QDP, then the production of TNF- $\alpha$ and IL- 6 were measured by ELISA; and protein molecules such as COX-2, iNOS, IKB- $\alpha$ were determined by Western blot.
\end{abstract}

Results: Oral administration of QDP at dosages of 1.54 and $3.08 \mathrm{~g} / \mathrm{kg}$ significantly reduced disease activity index on day $12(P<0.001$ for $1.54 \mathrm{~g} / \mathrm{kg}$ and $P<0.0008$ for $3.08 \mathrm{~g} / \mathrm{kg})$, colon shortening $(P=0.012$ for $1.54 \mathrm{~g} / \mathrm{kg}, P=0.001$ for $3.08 \mathrm{~g} / \mathrm{kg}$ ), histological damage ( $P<0.001$ for $1.54 \mathrm{~g} / \mathrm{kg}, P<0.001$ for $3.08 \mathrm{~g} / \mathrm{kg}$ ) and colonic myeloperoxidase activity $(P=0.002$ for $1.54 \mathrm{~g} / \mathrm{kg}, P<0.001$ for $3.08 \mathrm{~g} / \mathrm{kg}$ ) of DSS-treated mice. Moreover, QDP treatment (1.54 and $3.08 \mathrm{~g} /$ $\mathrm{kg}$ ) significantly decreased DSS-induced infiltration of macrophages, and production of TNF- $\alpha(P=0.005$ for $1.54 \mathrm{~g} /$ $\mathrm{kg}, P=0.002$ for $3.08 \mathrm{~g} / \mathrm{kg}$ ), IL-1 $\beta$ ( $P=0.008$ for $1.54 \mathrm{~g} / \mathrm{kg}, P=0.002$ for $3.08 \mathrm{~g} / \mathrm{kg}$ ) and IL-6 $(P=0.011$ for $1.54 \mathrm{~g} / \mathrm{kg}$, $P=0.004$ for $3.08 \mathrm{~g} / \mathrm{kg}$ ) in colonic tissues, and also reduced serum MCP-1 levels $(P=0.001$ for $1.54 \mathrm{~g} / \mathrm{kg}, P<0.001$ for $3.08 \mathrm{~g} / \mathrm{kg}$ ). In RAW264.7 cells, QDP significantly suppressed LPS-induced production of TNF- $\alpha$ and IL-6 (Both $P<0.001$ for $1.0 \mu \mathrm{g} / \mathrm{mL}$ QDP treatment) and expression levels of COX-2 ( $P=0.002$ and $P=0.001$ for 1 and $3 \mu \mathrm{g} / \mathrm{mL}$ QDP treatment, respectively) and iNOS ( $P<0.001$ for $3 \mu \mathrm{g} / \mathrm{mL}$ QDP treatment) by inhibiting $\mathrm{I}_{\kappa} \mathrm{B}-\alpha$ degradation $(P=0.007$ and $P=0.004$ for 1 and $3 \mu \mathrm{g} / \mathrm{mL}$ QDP treatment, respectively) and NF-KB p65 nuclear translocation.

Conclusion: QDP suppressed the inflammatory responses of colonic macrophages in DSS-induced UC in mice and LPS-induced RAW264.7 cells.

\footnotetext{
*Correspondence: bianzxiang@gmail.com

${ }^{1}$ School of Chinese Medicine, Hong Kong Baptist University, Hong Kong,

Full list of author information is available at the end of the article
} provided you give appropriate credit to the original author(s) and the source, provide a link to the Creative Commons license, and indicate if changes were made. The Creative Commons Public Domain Dedication waiver (http://creativecommons.org/ publicdomain/zero/1.0/) applies to the data made available in this article, unless otherwise stated. 


\section{Background}

Ulcerative colitis (UC), a subtype of inflammatory bowel disease (IBD), is a chronic uncontrolled inflammatory condition of the intestinal mucosa [1], progressively increasing in the incidence rates worldwide $[2,3]$. The refractory relapses are due to lack of effective treatment [4]. Current medical therapies for UC mainly focus on inducing remission and preventing relapse [5]. Aminosalicylates [sulfasalazine (SASP) and 5-aminosalicylic acid (5-ASA)], corticosteroid (prednisolone) and thiopurines (azathioprine and 6-mercaptopurine) are commonly recommended as the standard treatments for UC patients [6]. In addition, infliximab and tacrolimus have been used for treating UC patients since 1998 and 2006, respectively [7].

IBD is subject to environmental factors, genetic determinants, microbial exposures and immunoregulatory defects [8]. IBD develops when an excessive immunological reaction in the mucosal immune system respond towards luminal antigens such as dietary factors, commensal bacteria or both in genetically susceptible hosts [9]. Innate immunity is involved during the onset and in the regulation of the severity of IBD. In the development of IBD, the innate immune response increased levels of proinflammatory cytokines and chemokines, including TNF- $\alpha$, IL- $1 \beta$ and IL- 6 , exaggerating adaptive immune responses, and resulting in tissue injury and clinical symptoms $[10,11]$.

A significant increase in the number of macrophages was observed in the inflamed tissue and peripheral blood vessels of IBD patients [12, 13]. During the development of acute colitis in animal models, accumulated macrophages were also observed in the inflamed gut $[14,15]$. Interleukins or growth factors at sites of inflammation activated clusters of macrophages, which subsequently secrete a variety of proinflammatory cytokines, resulting in persistent intestinal inflammation [16]. Depletion of macrophages in dextran sulfate sodium (DSS)-induced colitis in mice halted the development of colitis [17]. Thus, suppressing intestinal macrophages could be a promising therapeutic approach to treating IBD.

Qing-dai powder (QDP) is a herbal medicinal formula comprising Indigo naturalis (Qing-dai) and dried alum $(K u-f a n)$, for treating hematemesis and hemorrhinia [18]. QDP and its modified formulas are clinically used to treat colitis in China [19-21]. From 2009 to 2013, we at Hong Kong Baptist University Mr. and Mrs. Chan Hon Yin Chinese Medicine Specialty Clinic and Good Clinical Practice Centre prescribed QDP to patients with intractable UC in clinical practice who had failed to respond to treatment with 5-ASA, prednisolone or infliximab. We gave QDP at a dosage of $7.5 \mathrm{~g} /$ day (loaded in capsules, orally, twice a day) for 1-2 weeks. There was a study on indirubin $3^{\prime}$-monoxime, a derivative compound of the active component indirubin isolated from $I$. naturalis, observed the compound significantly inhibited the production of pro-inflammatory mediators induced by LPS in RAW264.7 cells through down-regulating NF- $\mathrm{KB}$ and JNK signaling pathways [22]. The regulation of macrophage function could be involved in the effect of QDP. The effects and potential mechanism of QDP has not yet been assessed in animal studies.

This study aims to investigate the effects and potential mechanism of QDP on DSS-induced acute colitis in mice and to examine the regulatory effects of QDP on macrophages.

\section{Methods \\ Materials}

DSS (molecular weight: 36,000-50,000 Daltons) was purchased from MP Biologicals (Santa Ana, USA). Dimethylsulphoxide (DMSO), lipopolysaccharide (LPS) (Escherichia coli Serotype 055:B5), sulfasalazine (SASP) (purity $\geq 98 \%$ ), hexadecyltrimethylammonium bromide, hematoxylin, eosin, $\mathrm{O}$-dianisidine dihydrochloride, protease inhibitor cocktails and hydrogen peroxide were purchased from Sigma-Aldrich (St, Louis, MO, USA). Fetal bovine serum, L-glutamine, penicillin, streptomycin and RPMI 1640 cell culture medium were purchased from Invitrogen (Carlsbad, CA, USA). Antibodies against COX-2, iNOS, IкB $\alpha$ and $\mathrm{p} 65$ and $\beta$-actin were supplied from Cell Signaling Technology, Inc. (Beverly, MA, USA). TNF- $\alpha$, IL-1 $\beta$, and IL-6 ELISA kits were purchased from eBioscience (San Diego, CA, USA). Cy5.5 PerCP antimouse CD11b, FITC anti-mouse F4/80 were purchased from BD Pharmingen (San Diego, CA, USA). FITCconjugated donkey anti-rabbit IgG antibody was purchased from Santa Cruz Biotechnology (Santa Cruz, CA, USA). WesternBright ${ }^{\mathrm{TM}} \mathrm{ECL}$ was supplied from Advansta (Menio Park, CA, USA).

\section{Preparation of QDP}

The ratio of $I$. naturalis and dried alum in QDP is 2:1. Two Chinese medicinal raw herbs were obtained from the dispensary of Traditional Chinese Medicine, Clinical Division, School of Chinese Medicine, Hong Kong Baptist University, Hong Kong. These two Chinese medicinal materials were authenticated by Dr. Hu-Biao Chen (School of Chinese Medicine, Hong Kong Baptist University, Hong Kong) according to the Chinese Pharmacopoeia (version 2010) and other references [23-25]. Voucher specimens (nos. TCM-0110-Q01, TCM-0110-Q02) are stored in our Research Laboratory, School of Chinese Medicine, Hong Kong Baptist University, Hong Kong. Two herbs were mixed, powdered to homogeneous size in a mill and sieved through a 
120-mesh filter. Each sample was exactly weighed, ultrasonically extracted with DMSO in a KQ-2200DB ultrasonic cleaner bath (Kunshan Ultrasound Instrument Co., Ltd., Jiangsu, China), and filtered through a syringe filter for subsequent UPLC-QTOF-MS analysis and cell culture treatment. For animal study, QDP was freshly suspended in $0.5 \%$ sodium carboxymethylcellulose $(\mathrm{CMC}-\mathrm{Na})$ in distilled water prior to oral feeding to mice.

\section{Ultra-performance liquid chromatography quadrupole} time-of-flight mass spectrometry (UPLC-QTOF-MS) analysis The components in QDP were identified by UPLCQTOF-MS. Chromatographic separation was performed by an Agilent 1290 Infinity UPLC system (Santa Clara, CA, USA), equipped with a binary solvent delivery system, a standard auto-sampler and photodiode array detectors (DAD). A $100 \mathrm{~mm} \times 2.1 \mathrm{~mm}$ ACQUITY BEH $\mathrm{C}_{18}$ 1.7- $\mu \mathrm{m}$ column (Waters Corp., Milford, MA, USA) was used to separate the components of QDP. The mobile phase consisted of (A) $0.1 \%$ formic acid in water and (B) $0.1 \%$ formic acid in acetonitrile. A linear gradient was optimized as follows (flow rate, $0.40 \mathrm{~mL} / \mathrm{min}$ ): $0-2.5 \mathrm{~min}, 2-5 \% \mathrm{~B} ; 2.5-$ $10 \mathrm{~min}, 5-35 \% \mathrm{~B} ; 10-20 \mathrm{~min}, 35-75 \% \mathrm{~B} ; 20-23 \mathrm{~min}$, $75-100 \%$ B; 23-26 min, $100 \%$ B; 26-26.1 min, $100-2 \% \mathrm{~B} ; 26.1-30 \mathrm{~min}, 2 \% \mathrm{~B}$. The injection volume was $2 \mu \mathrm{L}$ and the column temperature was maintained at $40{ }^{\circ} \mathrm{C}$ in each run. Mass spectrometry was performed by an Agilent 6540 ultra-high definition (UHD) QTOF mass spectrometer, equipped with a Jet Stream electrospray ionization (ESI) source. Parameters for the Jet Stream technology were set with the superheated nitrogen sheath gas temperature at $350{ }^{\circ} \mathrm{C}$ and with a flow rate at $10 \mathrm{~L} / \mathrm{min}$. ESI conditions were set as follows: negative ion mode, capillary $4500 \mathrm{~V}$, nebulizer $1.85685 \times 10^{6} \mathrm{kPa}$, drying gas $8 \mathrm{~L} / \mathrm{min}$, gas temperature $300{ }^{\circ} \mathrm{C}$, nozzle voltage $300 \mathrm{~V}$, skimmer voltage $65 \mathrm{~V}$; octapole RF peak $600 \mathrm{~V}$, fragmentor $175 \mathrm{~V}$. Mass spectra were recorded across the range $\mathrm{m} / z$ 100-1700 with accurate mass measurement of all mass peaks. A sprayer with a reference solution was used for continuous calibration in negative ion mode with reference masses at $m / z 112.9856$ and 966.0007. The full-scan and MS/MS data were processed with Agilent Mass Hunter Workstation software (version B.02.00) (Santa Clara, CA, USA).

\section{Cell culture}

RAW264.7 murine macrophage cells were obtained from the American Type Culture Collection (ATCC No. TIB71). The cell line was cultured in RPMI 1640 cell culture medium supplemented with $10 \%$ (v/v) fetal bovine serum, $2 \mathrm{mM}$ L-glutamine, $100 \mathrm{U} / \mathrm{mL}$ penicillin $\mathrm{G}$ and
$100 \mu \mathrm{g} / \mathrm{mL}$ streptomycin. The cells were incubated in a humidified $5 \% \mathrm{CO}_{2}$ incubator at $37^{\circ} \mathrm{C}$.

\section{Animals}

Seven to eight-week-old male C57BL/6 mice weighing 20-24 g were purchased from the Laboratory Animal Services Center, The Chinese University of Hong Kong. The animals were fed a standard rodent diet with free access to water, and were kept in rooms maintained at $21-23{ }^{\circ} \mathrm{C}$ with a $12 \mathrm{~h}$ light/dark cycle following international recommendations. All experimental protocols were approved by the Animal Ethics Committees of Hong Kong Baptist University, in accordance with "Institutional Guidelines and Animal Ordinance" (Department of Health, Hong Kong Special Administrative Region).

\section{Induction of colitis and treatment}

Acute colitis was induced by oral administration of $2.0 \%$ $(\mathrm{w} / \mathrm{v})$ DSS dissolved in drinking water, for 5 days according to Wirtz et al. [26]. Mice of each experimental group were monitored every day to confirm that they consumed equal volumes of DSS-containing water.

Two sets of experiments were performed. For the first one, 50 colitic mice were arbitrarily allocated into 5 groups: DSS model group, sulfasalazine (SASP, positive reference agent)-treated group, and three QDP-treated groups $(\mathrm{n}=10)$. A vehicle control group with nine normal mice received drinking water without DSS throughout the entire experimental period. Consistent with clinical treatment, QDP was administrated orally to colitic mice at doses of $0.77,1.54$ or $3.08 \mathrm{~g} / \mathrm{kg} /$ day, comparable with the clinical dosages used in human UC patients. SASP was used as a positive reference agent and it was given at $0.20 \mathrm{~g} / \mathrm{kg} /$ day according to Kim et al. [27]. The gavage volume was $0.4 \mathrm{~mL}$.

For the second set of experiments to immunophenotype colonic macrophages in colonic lamina propria, twelve colitic mice were arbitrarily allocated into 2 groups: DSS model group $(\mathrm{n}=6)$ and $1.54 \mathrm{~g} / \mathrm{kg}$ QDPtreated group $(n=6)$. A vehicle control group of 5 normal mice received drinking water only during the entire experimental period. Both SASP and QDP were dissolved in $0.5 \%$ sodium carboxymethylcellulose (CMC-Na) solution and administrated orally to the mice for 7 days after the onset of colitis. The vehicle control group and DSS model group were fed with $0.4 \mathrm{~mL}$ of $0.5 \%$ CMC-Na solution instead of SASP or QDP.

\section{Evaluation of disease activity index (DAI)}

Body weight, stool consistency and rectal bleeding were recorded daily. The DAI was determined by combining the scores of (1) body weight, (2) stool consistency and (3) rectal bleeding [28]. 


\section{Histological analysis}

Colon tissues were harvested and fixed in $4.0 \%$ paraformaldehyde. Tissue sections were prepared by conventional tissue processing methods, stained with hematoxylin and eosin (H\&E), and examined under the light microscope. Colonic damage was assessed as described previously [28].

\section{Determination of colonic myeloperoxidase (MPO) activity} MPO activity was measured as described in our previous study [28]. One unit of MPO activity was defined as the amount of enzyme present that produced a change in optical density of $1.0 \mathrm{U} / \mathrm{min}$ at $25^{\circ} \mathrm{C}$ in the final reaction volume. The results were normalized to equal protein levels and quantified as units/mg protein.

\section{Immunohistochemical analysis}

Colonic tissues were fixed in $4.0 \%$ buffered paraformaldehyde, embedded in paraffin and sectioned into 5 - $\mu$ m-thick slices. Sectioned samples were deparaffinized in xylene, rehydrated in a series of graded alcohol, and subjected to antigen retrieval. Antigens were retrieved by incubation with protease K solution (1: 100) for $20 \mathrm{~min}$.

Endogenous peroxidase was quenched with $3.0 \%$ hydrogen peroxide in methanol for $30 \mathrm{~min}$. Sections were further blocked with $3.0 \%$ bovine serum albumin (BSA) in PBS, exposed to $0.5 \%$ Triton X-100 for $1 \mathrm{~h}$ for reducing nonspecific antibody binding and incubated with mouse F4/80 antibody (AbD serotec, Raleigh, North Carolina, USA) at $4{ }^{\circ} \mathrm{C}$ overnight. The sections were washed with PBS three times, incubated with biotinylated antirabbit immunoglobulins, followed by peroxidase-labeled streptavidin, and 3, 3'-diaminobenzidine chromogen substrate added to make antibody binding visible according to the protocol of the LSAB kit (LSAB-DAKO, Copenhagen, Denmark). Sections were then washed with PBS and counterstained with hematoxylin. After dehydration with a series of increasingly concentrated ethanol, sections were mounted with neutral gum. Five random fields at $400 \times$ magnification were counted in each sectioned sample by a researcher blinded to the treatment. The number of macrophages per $\mu \mathrm{m}^{2}$ of mucosa was quantified by the Image J software (National Institutes of Health, Bethesda, Maryland, USA).

\section{Immunophenotyping of colonic macrophages}

Colonic lamina propria cells were isolated as previously described with slight modifications [29, 30]. The colons were removed from mice immediately after euthanasia. Subsequently, the colonic tissues were immersed in DMEM containing $100 \mathrm{U} / \mathrm{mL}$ of penicillin and $100 \mu \mathrm{g} /$ $\mathrm{mL}$ of streptomycin, dissected longitudinally and cut into 0.5-1-cm pieces. Then, intestinal epithelial cells were dissociated by incubation with $\mathrm{Ca}^{2+}$ and $\mathrm{Mg}^{2+}$-free HBSS containing $5 \mathrm{mM}$ EDTA and $1 \mathrm{mM}$ DTT for $20 \mathrm{~min}$ at $37{ }^{\circ} \mathrm{C}$, twice. After thorough washing with PBS, colonic tissues were then incubated with digestion buffer (RPMI 1640 containing $3 \mathrm{mg} / \mathrm{mL}$ dispase II, $0.5 \mathrm{mg} / \mathrm{mL}$ collagenase $\mathrm{D}$, and $0.5 \mathrm{mg} / \mathrm{mL}$ DNase I) for $30 \mathrm{~min}$ at $37^{\circ} \mathrm{C}$, twice. Finally, the cells were labeled with anti-CD11b and anti-F4/80 antibodies, and analyzed by flow cytometry. Appropriate isotype-matched IgGs were used as negative controls.

\section{Enzyme-linked immunosorbent assay (ELISA) analysis}

The cytokines TNF- $\alpha$, IL- $1 \beta$ and IL- 6 in the culture supernatants of RAW264.7 cells and colonic tissues and the chemokine monocyte chemoattractant protein-1 $(\mathrm{MCP}-1)$ in serum samples were measured with TNF- $\alpha$, IL-1 $\beta$, IL- 6 and MCP ELISA kits, respectively (eBioscience, San Diego, CA, USA) according to the manufacturer's protocols.

\section{Western blot analysis}

After treatment with a range of concentrations of QDP $(0.3-3 \mu \mathrm{g} / \mathrm{mL})$ in the presence or absence of $1 \mu \mathrm{g} / \mathrm{mL}$ LPS, RAW264.7 cells were analyzed by immunoblotting as described previously [31]. Primary antibodies that

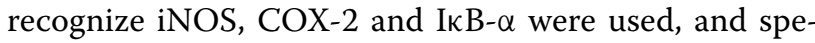
cific proteins were detected by WesternBright ${ }^{\mathrm{TM}}$ ECL. Equal loading was assessed by a $\beta$-actin antibody, and the amount of total protein present was normalized to the level of $\beta$-actin.

\section{Cellular localization of nuclear factor kappa B (NF-кB) p65}

RAW264.7 cells were cultured directly on glass cover slips in a $35-\mathrm{mm}$ dish for $24 \mathrm{~h}$ and pretreated with QDP for $1 \mathrm{~h}$ in the presence or absence of $1 \mu \mathrm{g} / \mathrm{mL}$ LPS. Cells were fixed with $4 \%$ paraformaldehyde, treated with $0.2 \%$ Triton X-100, and blocked with $3 \%$ BSA. Subsequently, cells were incubated with a rabbit anti-NF- $\kappa$ B p65 polyclonal antibody $(1: 100)$ at $4{ }^{\circ} \mathrm{C}$ overnight. After extensive washing with $\mathrm{PBS}$, cells were further incubated with a secondary FITC-conjugated donkey anti-rabbit IgG antibody (1:100) for $1 \mathrm{~h}$ at room temperature. Nuclei were counterstained with DAPI solution $(1 \mu \mathrm{g} / \mathrm{mL})$, and cells were analyzed by a fluorescence microscope (Carl Zeiss, Oberkochen, Germany).

\section{Statistical analysis}

The data were presented as mean \pm standard deviation (SD). Statistical differences among groups were evaluated by oneway analysis of variance (ANOVA) and Duncan's multiple range test by SPSS 16.0 statistical software (SPSS Inc., Chicago, IL, USA). $P$ values $<0.05$ were considered statistically significant. Dose-dependence was visually determined. 


\section{Results}

\section{Identification of chemical components of QDP}

Under the optimized conditions [32], the major components in QDP were well separated and detected within 30 min (Table 1). Taking retention time (tR), $m / z$, ultraviolet (UV) absorption characteristics (lambda max), and relevant references into consideration, 27 peaks representing individual chemical components were identified. The representative chromatograms, monitored by DAD and MS, are shown in Fig. 1.

\section{QDP attenuates the severity of DSS-induced colitis}

Oral administration of $2.0 \%$ DSS in drinking water resulted in high mortality; up to $30.0 \%$ of the total mice in the DSS model group died. QDP treatment could reduce the mortality rate of DSS-treated mice, to 20.0, 10.0 and $10.0 \%$ for low-, medium- and high-dose QDPtreated groups, respectively (Fig. 2a). Starting from day 5 , DSS resulted in rapid loss of body weight and serious clinical disease symptoms (diarrhea and occult fecal blood) in C57BL/6 J mice, and lasted 3-4 days. After that, mice began to recover. QDP treatment improved body weight recovery and DAI of DSS-treated mice, particularly in the medium- and high-dose QDP treatment groups when compared with the DSS model group (both $P<0.001$ ) (Fig. 2b, c). In addition, the DSS-induced model of colitis is associated with a marked decrease in colon length [28]. Treatment with QDP significantly prevented colon shortening in a dose-dependent manner ( $P=0.020, P=0.012, P=0.001$, respectively) (Fig. $2 \mathrm{~d}$ ).

\section{QDP decreases colonic tissue damage and reduces colonic MPO activity}

As shown in Fig. 3, 2.0 \% DSS in drinking water caused extensive colonic tissue damage, including inflammatory cell infiltration, lesion formation and crypt destruction. Mice receiving QDP treatment showed less colonic damage. Scores of the histological changes are displayed in Fig. 3g. The score was significantly higher for the DSS model group than that for the vehicle-treated control group, i.e., reducing inflammation and mucosal and crypt damage in the colon, in

Table 1 Main components of QDP

\begin{tabular}{|c|c|c|c|}
\hline Peak & $\mathrm{tR}(\mathrm{min})$ & Assigned identity & Molecular formula \\
\hline 1 & 0.999 & Butanedioic acid & $\mathrm{C}_{4} \mathrm{H}_{6} \mathrm{O}_{4}$ \\
\hline 2 & 5.775 & Isatin & $\mathrm{C}_{8} \mathrm{H}_{5} \mathrm{NO}_{2}$ \\
\hline 3 & 5.908 & 2,3-Dihydro-4-hydroxy-2-oxo-1H-indole-3-acetic acid & $\mathrm{C}_{10} \mathrm{H}_{8} \mathrm{~N}_{2} \mathrm{O}_{2}$ \\
\hline 4 & 6.511 & Deoxyvascinone & $\mathrm{C}_{11} \mathrm{H}_{10} \mathrm{~N}_{2} \mathrm{O}$ \\
\hline 5 & 7.729 & $10 \mathrm{H}$-indolo $[3,2-b]$ quinoline & $\mathrm{C}_{15} \mathrm{H}_{10} \mathrm{~N}_{2}$ \\
\hline 6 & 8.436 & 2,3-Dihydro-3,4-dihydroxy-2-oxo-1H-indole-3-acetonitrile, 3-Cyanomethyl-3,4-dihydroxyoxindole & $\mathrm{C}_{10} \mathrm{H}_{8} \mathrm{~N}_{2} \mathrm{O}_{3}$ \\
\hline 7 & 8.856 & 3-(2-Hydroxyphenyl)-4(3H)-quinazolinone & $\mathrm{C}_{14} \mathrm{H}_{10} \mathrm{~N}_{2} \mathrm{O}_{2}$ \\
\hline 8 & 8.995 & 10H-indolo[3,2-b]quinoline-11-carboxylic acid amide & $\mathrm{C}_{16} \mathrm{H}_{11} \mathrm{~N}_{3} \mathrm{O}$ \\
\hline 9 & 9.589 & Tryptanthren & $\mathrm{C}_{15} \mathrm{H}_{8} \mathrm{~N}_{2} \mathrm{O}_{2}$ \\
\hline 10 & 11.515 & Syringin & $\mathrm{C}_{17} \mathrm{H}_{24} \mathrm{O}_{9}$ \\
\hline 11 & 11.909 & 3-(2-Carboxyphenyl)-4(3H)-quinazolinone & $\mathrm{C}_{15} \mathrm{H}_{10} \mathrm{~N}_{2} \mathrm{O}_{3}$ \\
\hline 12 & 13.240 & Indigo & $\mathrm{C}_{16} \mathrm{H}_{10} \mathrm{~N}_{2} \mathrm{O}_{2}$ \\
\hline 13 & 13.972 & Indican & $\mathrm{C}_{14} \mathrm{H}_{17} \mathrm{NO}_{6}$ \\
\hline 14 & 14.185 & Indirubin & $\mathrm{C}_{16} \mathrm{H}_{10} \mathrm{~N}_{2} \mathrm{O}_{2}$ \\
\hline 15 & 14.658 & 2-[Cyano(3-indolyl)methylene]-3-indolone & $\mathrm{C}_{18} \mathrm{H}_{11} \mathrm{~N}_{3} \mathrm{O}$ \\
\hline 16 & 16.612 & 8,11,12-Trihydroxy-9-octadecenoic acid & $\mathrm{C}_{19} \mathrm{H}_{36} \mathrm{O}_{5}$ \\
\hline 17 & 17.883 & Anthranilic acid & $\mathrm{C}_{7} \mathrm{H}_{7} \mathrm{NO}_{2}$ \\
\hline 18 & 18.492 & Salicylic acid & $\mathrm{C}_{7} \mathrm{H}_{6} \mathrm{O}_{3}$ \\
\hline 19 & 19.161 & Octadecanoic acid & $\mathrm{C}_{18} \mathrm{H}_{36} \mathrm{O}_{3}$ \\
\hline 20 & 19.343 & Bisindigotin & $\mathrm{C}_{32} \mathrm{H}_{18} \mathrm{~N}_{4} \mathrm{O}_{2}$ \\
\hline 21 & 20.550 & Qingdainone & $\mathrm{C}_{23} \mathrm{H}_{13} \mathrm{~N}_{3} \mathrm{O}_{2}$ \\
\hline 22 & 20.854 & Betulin & $\mathrm{C}_{30} \mathrm{H}_{50} \mathrm{O}_{2}$ \\
\hline 23 & 21.463 & Sugiol & $\mathrm{C}_{20} \mathrm{H}_{28} \mathrm{O}_{2}$ \\
\hline 24 & 22.801 & Rotenol & $\mathrm{C}_{23} \mathrm{H}_{24} \mathrm{O}_{6}$ \\
\hline 25 & 23.417 & Sitosterol & $\mathrm{C}_{32} \mathrm{H}_{53} \mathrm{~N}_{7} \mathrm{O}_{2}$ \\
\hline 26 & 24.686 & Daucosterol & $\mathrm{C}_{35} \mathrm{H}_{60} \mathrm{O}_{6}$ \\
\hline 27 & 26.836 & Clerosterol & $\mathrm{C}_{29} \mathrm{H}_{48} \mathrm{O}$ \\
\hline
\end{tabular}




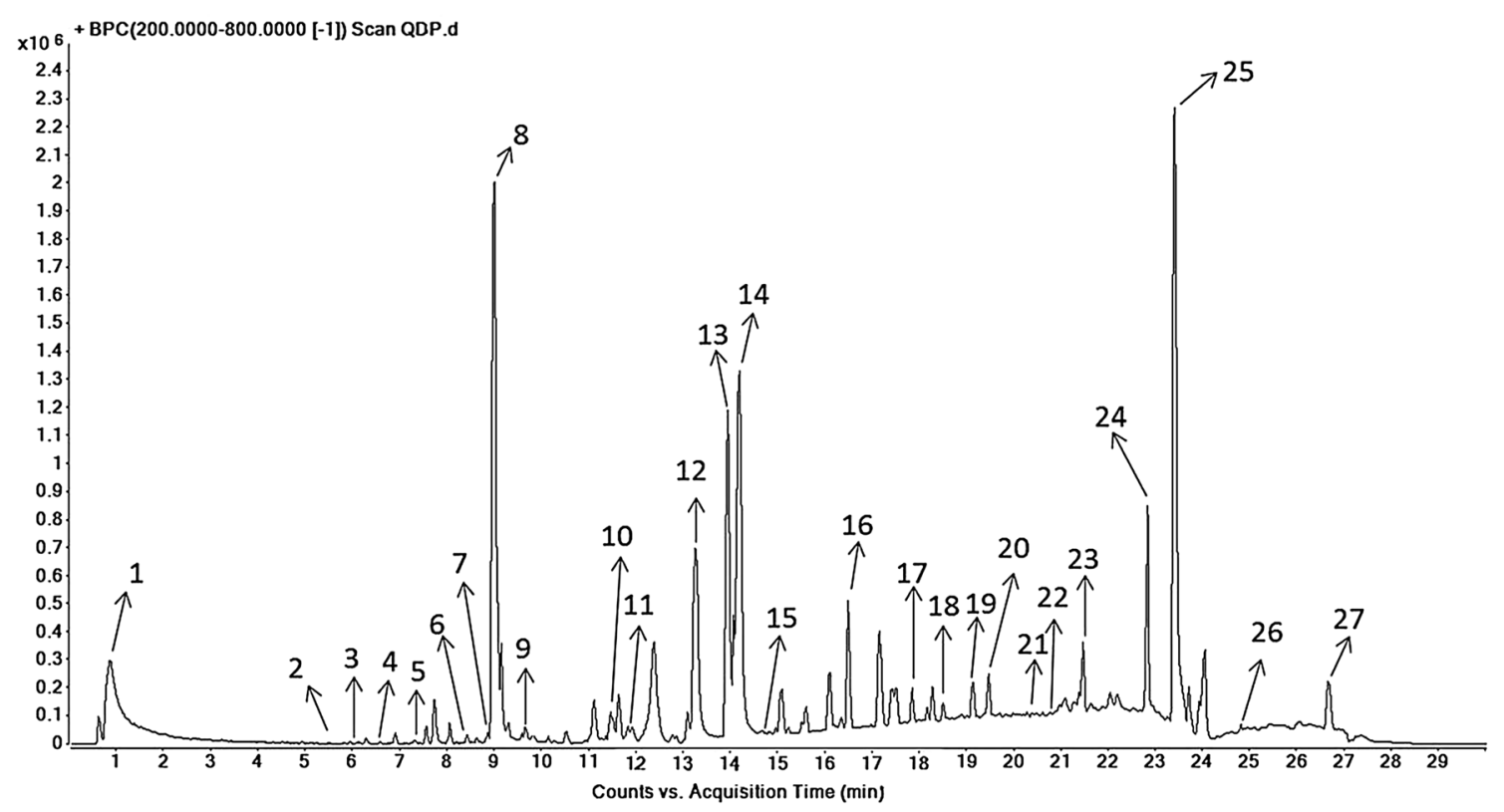

Fig. 1 Elementary particle flow graph (BPI) chromatogram monitored in positive ion mode for QDP

particular in those mice treated with medium and high doses of QDP (both $P<0.001$ ). Consistent with the histological scores, colonic MPO activity was greatly increased in the DSS model group $(P<0.001)$, whereas the MPO activities in the QDP-treated groups were significantly suppressed in a dose-dependent manner (Fig. 3h).

\section{QDP decreases infiltration of macrophages in the colon of DSS-treated mice}

The infiltration of macrophages in the colon was analyzed with the macrophage marker F4/80. The number of macrophages in the colons of model group mice was significantly higher than in the normal group $(P<0.001)$ (Fig. 4A). Compared with the model group, there were considerably fewer macrophages in the colons of QDPtreated mice $(P=0.003, P<0.001$ and $P<0.001$ for $0.77,1.54$ and $3.08 \mathrm{~g} / \mathrm{kg}$ QDP, respectively). Similar to the results of the immunohistochemical study, the number of macrophages was increased after DSS treatment $(P<0.001)$, and QDP at $1.54 \mathrm{~g} / \mathrm{kg}$ significantly decreased the recruitment of macrophages to the colon lamina propria of the DSS-treated mice $(P=0.004)$ in flow cytometry (Fig. 4B).
QDP suppresses colonic proinflammatory cytokine production and serum MCP-1 levels in DSS-treated mice Levels of macrophage-associated proinflammatory cytokines such as TNF- $\alpha$, IL- $1 \beta$ and IL- 6 were measured in the colonic tissues to ascertain the suppressive effects of QDP on colonic macrophages. The levels of colonic TNF- $\alpha$, IL- $1 \beta$ and IL- 6 were significantly higher in the DSS model group (all $P<0.001$ ), and QDP treatment significantly lowered the production of TNF- $\alpha$, IL-1 $\beta$ and IL- 6 in colonic tissue of DSS-treated mice (Fig. $5 \mathrm{a}-\mathrm{c}$ ). Oral administration of $2.0 \%$ DSS in drinking water resulted in a sharp increase of MCP-1 in the serum of DSS-treated mice. Treatment with QDP greatly reduced serum $\mathrm{MCP}-1$ levels in a dose-dependent manner (Fig. 5d).

\section{QDP inhibits LPS-induced TNF- $\alpha$ and IL-6 production and expression of iNOS and COX-2 in RAW264.7 cells}

Macrophages are a major source of proinflammatory cytokines, including TNF- $\alpha$, IL- $1 \beta$ and IL- 6 . We therefore evaluated the anti-inflammatory effect of QDP on LPSstimulated RAW264.7 cells (murine macrophage cell line). Treatment with LPS resulted in significantly increased production of proinflammatory cytokines (by 2.0-fold for 

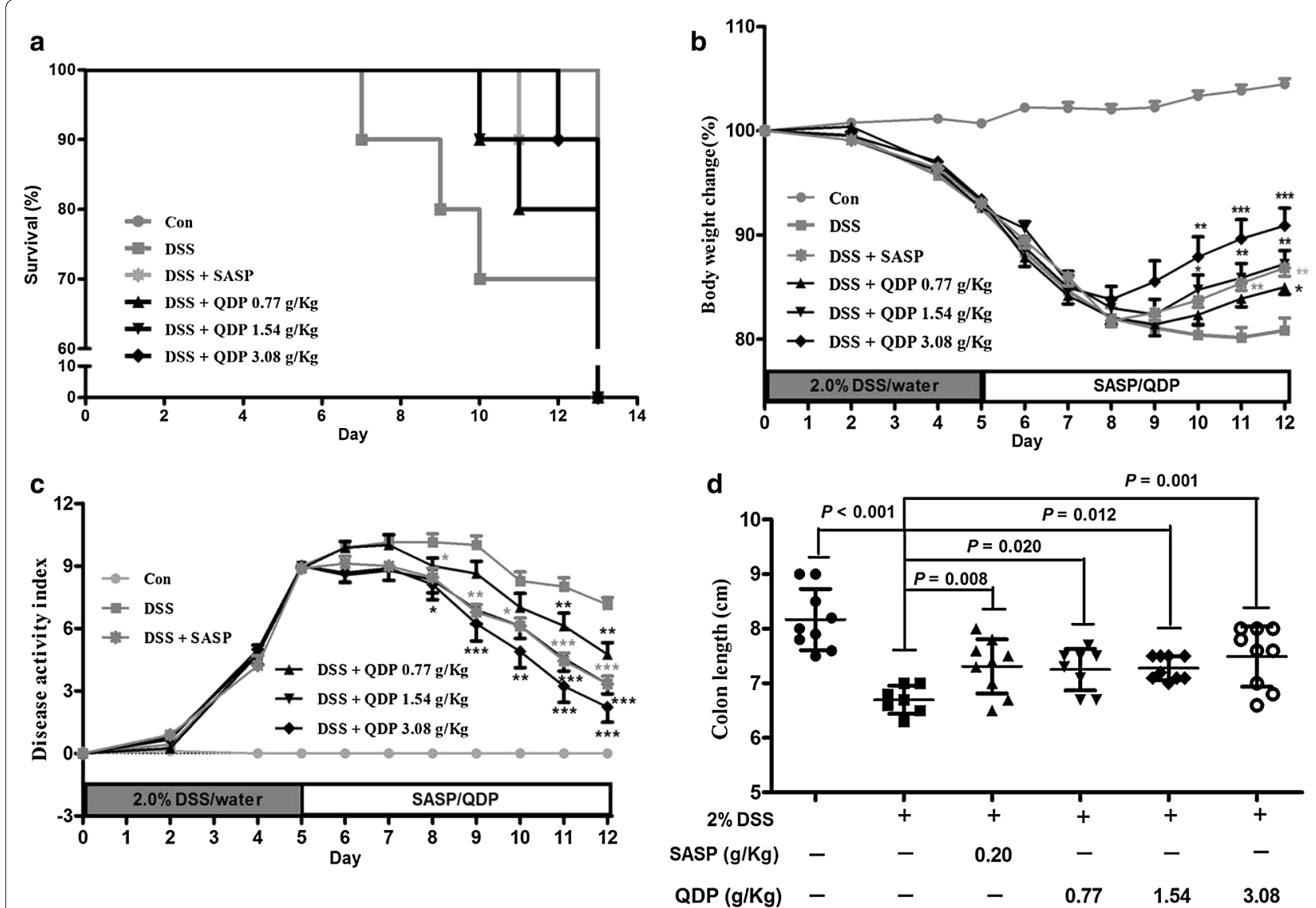

Fig. 2 Effects of QDP on mortality a body weight change; $\mathbf{b}$ disease activity index; $\mathbf{c}$ and colon length; and $\mathbf{d}$ of mice with DSS-induced colitis. Colitis was induced in all groups except control group. QDP and SASP were administered to mice from day 6 to 12. The change in body weight was taken as the difference between the body weight before induction of colitis and that immediately before sacrifice on day 13. Disease activity index was determined by combining scores of (1) body weight loss; (2) stool consistency; and (3) stool blood. On day 13, mice were sacrificed, and colon length was measured. Survival data of challenged mice were collected from 9 to 10 mice respectively, and other data were expressed as mean \pm SD ( $n=7-9) .{ }^{\# \#} P<0.001$, compared with control group; ${ }^{*} P<0.05,{ }^{* *} P<0.01$ and ${ }^{* *} P<0.001$, compared with DSS model group

TNF- $\alpha$; by 14.3-fold for IL-6) (both $P<0.001$ ) in culture supernatants of RAW264.7 cells, while QDP at a concentration of $1 \mu \mathrm{g} / \mathrm{mL}$ significantly inhibited LPS-induced production of TNF- $\alpha$ and IL-6 (both $P<0.001$ ) (Fig. 6a).

The activities of iNOS and COX-2 are the immediate modulators of $\mathrm{NO}$ and $\mathrm{PGE}_{2}$, respectively, produced by macrophages for the initiation and progression of IBD [33]. We investigated the effects of QDP on the expression of iNOS and COX-2 by Western blot analysis. Protein levels of iNOS and COX-2 were upregulated in response to LPS (Both $P<0.001$ ), and treatment with QDP resulted in dose-dependent inhibition of iNOS and COX-2 protein expression (Fig. 6b).

\section{QDP blocks LPS-induced ІкB- $\alpha$ degradation and p65} nuclear translocation

We examined the effect of QDP on LPS-induced degradation of IкB- $\alpha$ by Western blotting. The degradation of I $\mathrm{B}-\alpha$ after LPS treatment was inhibited by QDP in a dose-dependent manner (Fig. 7a).

Furthermore, we investigated the effect of QDP on LPS-induced p65 nuclear translocation by immunofluorescence. p65 was normally sequestered in the cytoplasm, while LPS induced p65 accumulation in the nucleus. However, pre-treatment with QDP abolished LPS-induced p65 translocation to the nucleus (Fig. 7b). 

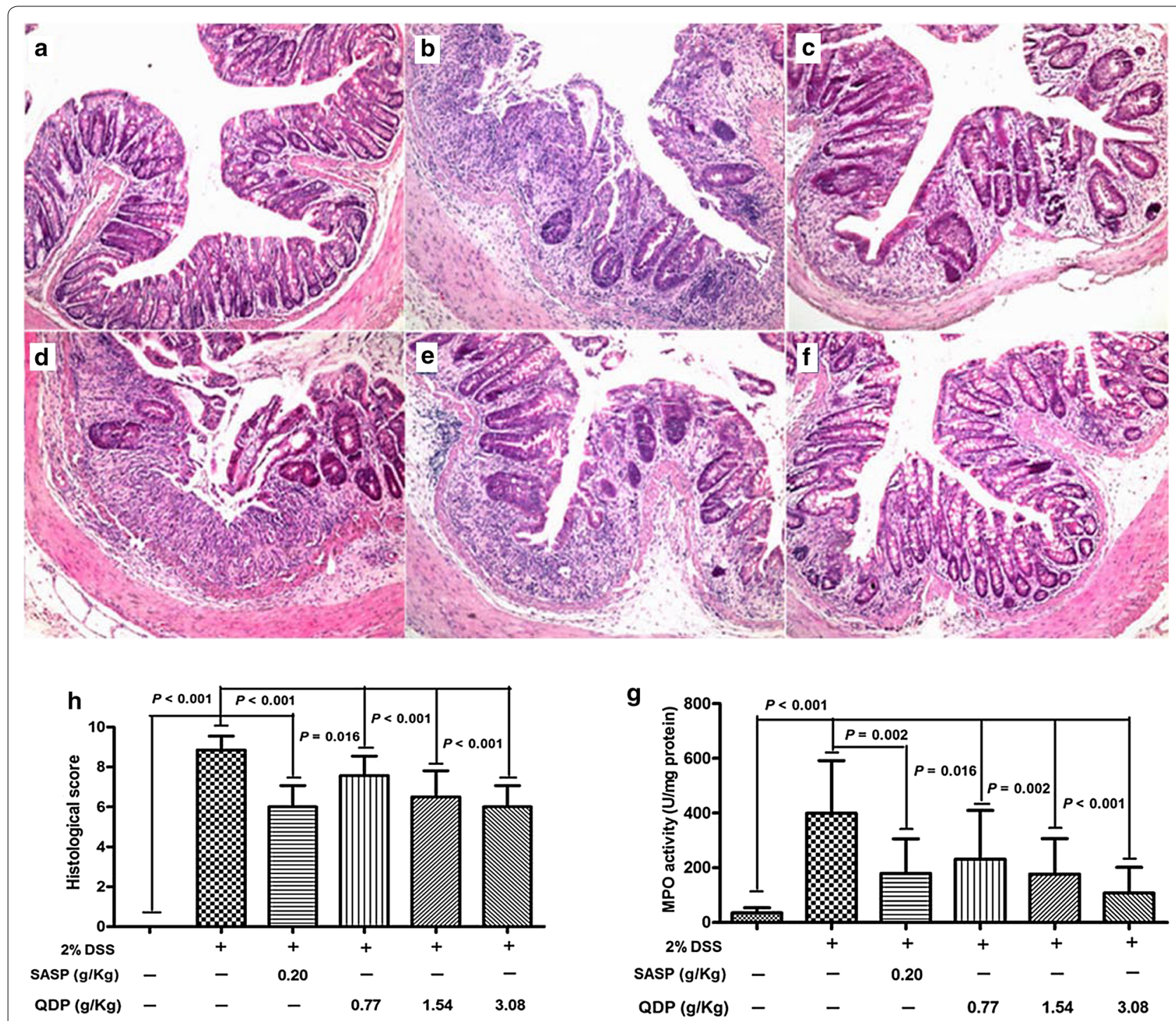

Fig. 3 Effects of QDP on histopathological changes and MPO activity in colon of mice with DSS-induced colitis. a control; b DSS model; c SASP; $\mathbf{d}$ $0.77 \mathrm{~g} / \mathrm{kg}$ QDP; $\mathbf{e} 1.54 \mathrm{~g} / \mathrm{kg}$ QDP; $\mathbf{f} 3.08 \mathrm{~g} / \mathrm{kg}$ QDP (magnification, $\times 100$ ); $\mathbf{g}$ histological score; and $\mathbf{h}$ MPO activity. Colitis was induced in all groups except control group. QDP and SASP were administered to mice from day 6 to 12 . On day 13, mice were sacrificed, and colonic tissue damage was evaluated by histopathological analysis (H\&E staining). MPO activity was determined in colonic homogenates. Data were expressed as mean \pm SD $(n=7-9)$

\section{Discussion}

Oral administration of QDP suppressed colonic macrophage recruitment and activation to attenuate the severity of DSS-induced colitis in mice, as evidenced by reduced mortality, clinical manifestations, colon shortening, histological damage and colonic myeloperoxidase activity.

The DSS-induced colitis mouse model is simple and reproducible, and is commonly used to study the pathogenesis of UC, and screen potential therapeutic interventions [34]. Using this model, we found that QDP could significantly attenuate clinical symptoms of DSS-treated mice including body weight loss, stool consistency and bleeding. Furthermore, QDP significantly prevented colon shortening and colon tissue damage induced by DSS. Oral administration of QDP could attenuate the colonic MPO activity of DSS-treated mice in a dose-dependent manner. 
A

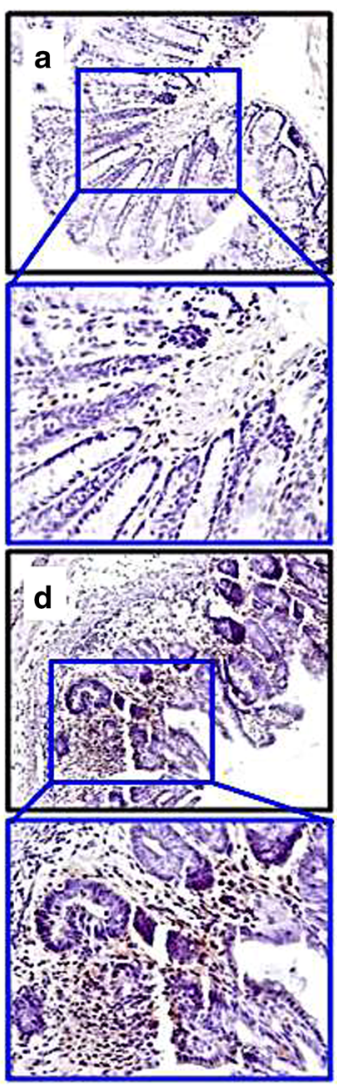

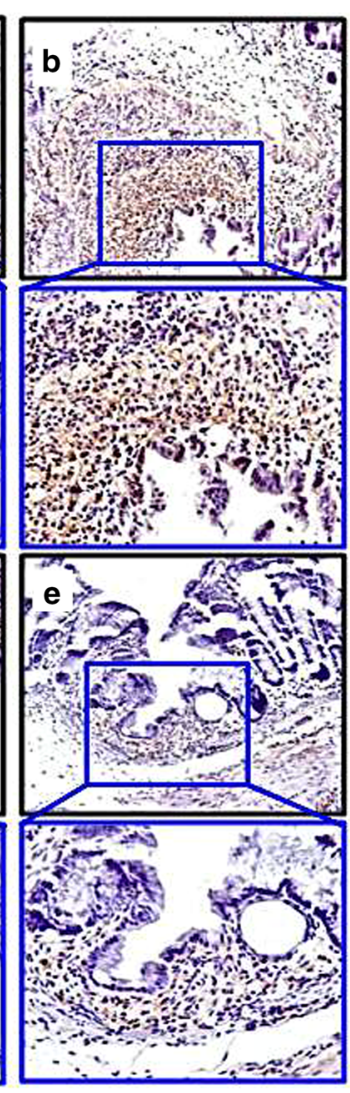

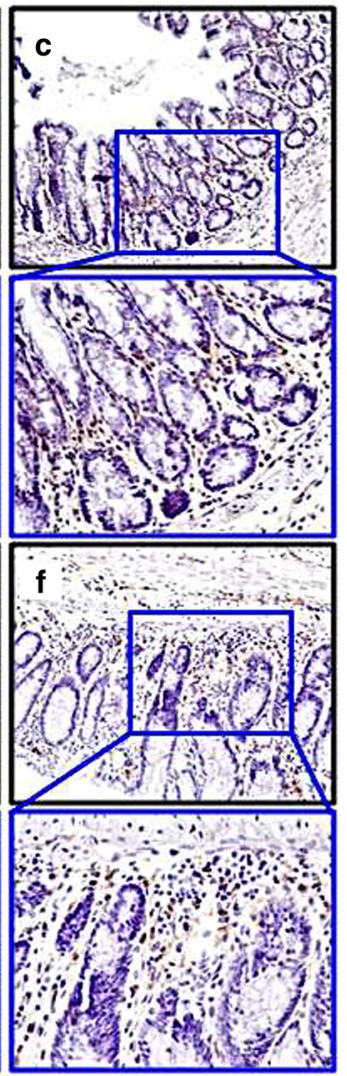

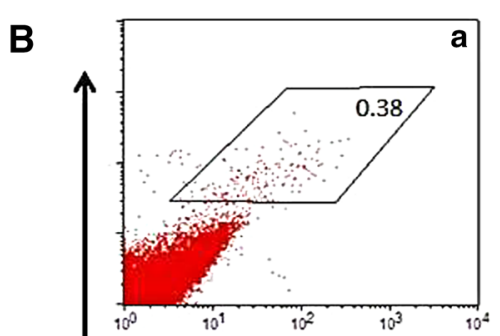

B

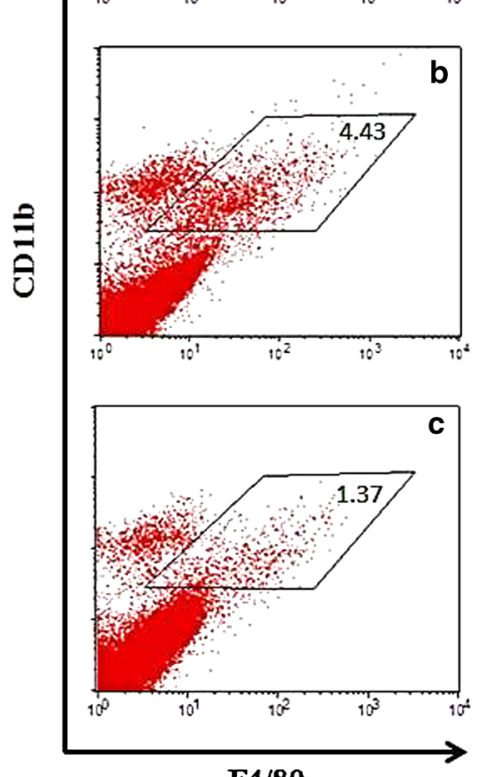

$\mathbf{F 4 / 8 0}$
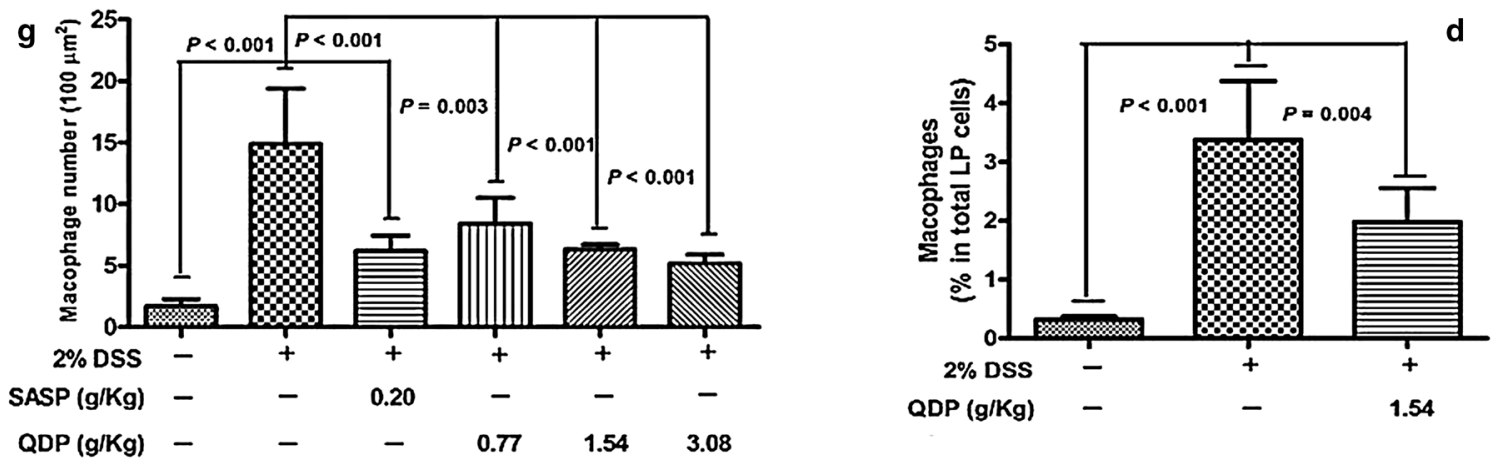

Fig. 4 Effects of QDP on macrophage infiltration in colons of DSS-treated mice. A Immunohistochemical (IHC) analysis of colonic macrophages by F4/80 marker [a-f representative images (a control; b DSS model; c SASP; $\mathbf{d} 0.77 \mathrm{~g} / \mathrm{kg}$ QDP; $\mathbf{e} 1.54 \mathrm{~g} / \mathrm{kg}$ QDP; and f $3.08 \mathrm{~g} / \mathrm{kg}$ QDP), $\mathbf{g}$ number of macrophages]; B flow cytometric analysis of macrophages in the colon lamina propria (LP) (a control; b DSS model; c $1.54 \mathrm{~g} / \mathrm{kg}$ QDP; and $\mathbf{d}$ percentage of macrophages in total LP cells). Colitis was induced in all groups except control group. QDP and SASP were administered to mice from day 6 to 12. On day 13 , mice were sacrificed. The colon section was evaluated by IHC analysis with F4/80 marker ( $\mathrm{n}=7-9)$. For flow cytometric analysis, the population of macrophage in lamina propria mononuclear cells from whole colonic tissue was determined by CD11b and F4/80 markers ( $n=5$ for normal control group, and $n=6$ for DSS-treated groups). Data were expressed as mean $\pm S D$

In the inflamed gut, macrophages secrete excessive proinflammatory cytokines to initiate the innate immune response and the consequential adaptive immune response $[14,16]$. In the present study, treatment with
2.0 \% DSS resulted in an increase of macrophages in colon tissues, and oral administration of QDP could significantly suppress macrophage accumulation. The accumulated macrophages in the inflamed colon were 

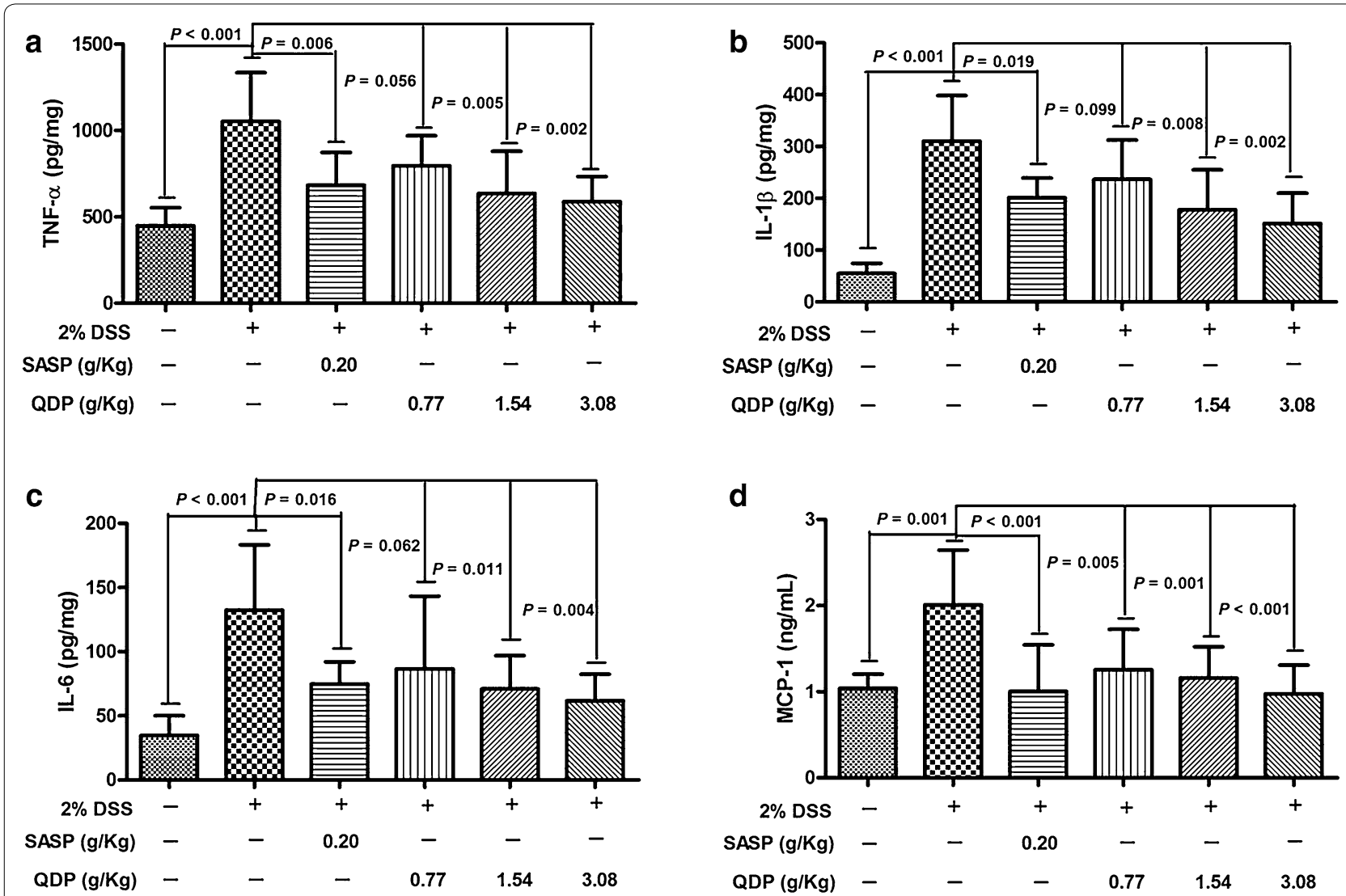

Fig. 5 Effects of QDP on colonic production of pro-inflammatory cytokines and serum MCP-1 level in DSS-treated mice (a colonic TNF- $\alpha$; b colonic IL-6; c colonic IL-1 $\beta$; and $\mathbf{d}$ serum MCP-1). QDP and SASP were administered to mice from day 6 to 12 . On day 13, mice were sacrificed, amounts of various cytokines in colonic homogenates and MCP-1 levels in serum were determined by ELISA. Data were expressed as mean \pm SD $(n=7-9)$

recruited and differentiated from Ly6C ${ }^{\text {hi }}$ monocytes in the bloodstream, and are different from resident intestinal macrophages and represent a proinflammatory phenotype [15]. Their recruitment was mediated by MCP-1, which binds to the chemokine receptor CCR2 on circulating monocytes to attract monocytes to inflamed tissues [15, 35]. We observed that $2.0 \%$ DSS treatment increased serum MCP-1 levels and QDP treatment could significantly reverse this increase. Accumulated colonic macrophages were activated in the context of gut inflammation, resulting in excessive secretion of proinflammatory cytokines, such as TNF- $\alpha$, IL- $1 \beta$ and IL-6, which exacerbate IBD [35]. QDP could significantly suppress the production of TNF- $\alpha$, IL- $1 \beta$ and IL- 6 in the colons of
DSS-treated mice. In RAW264.7 cells, QDP could significantly decrease LPS-induced TNF- $\alpha$ and IL- 6 production and expression of iNOS and COX-2 by inhibiting IкB- $\alpha$ degradation and NF- $\kappa \mathrm{B}$ p 65 translocation.

SASP is used clinically for mild-to-moderate UC patients via anti-inflammatory, immunomodulatory properties or both [36]. In the present study, QDP at a dose of $1.54 \mathrm{~g} / \mathrm{kg}$ exhibited an effect comparable with SASP $(200 \mathrm{mg} / \mathrm{kg})$ against DSS-induced colitis in mice. This beneficial effect was associated with its anti-inflammatory activity through suppression of colonic macrophage recruitment and activation. Therefore, QDP could be beneficial to mice, in addition to human, as a study model for developing effective pharmaceuticals to treat UC. 

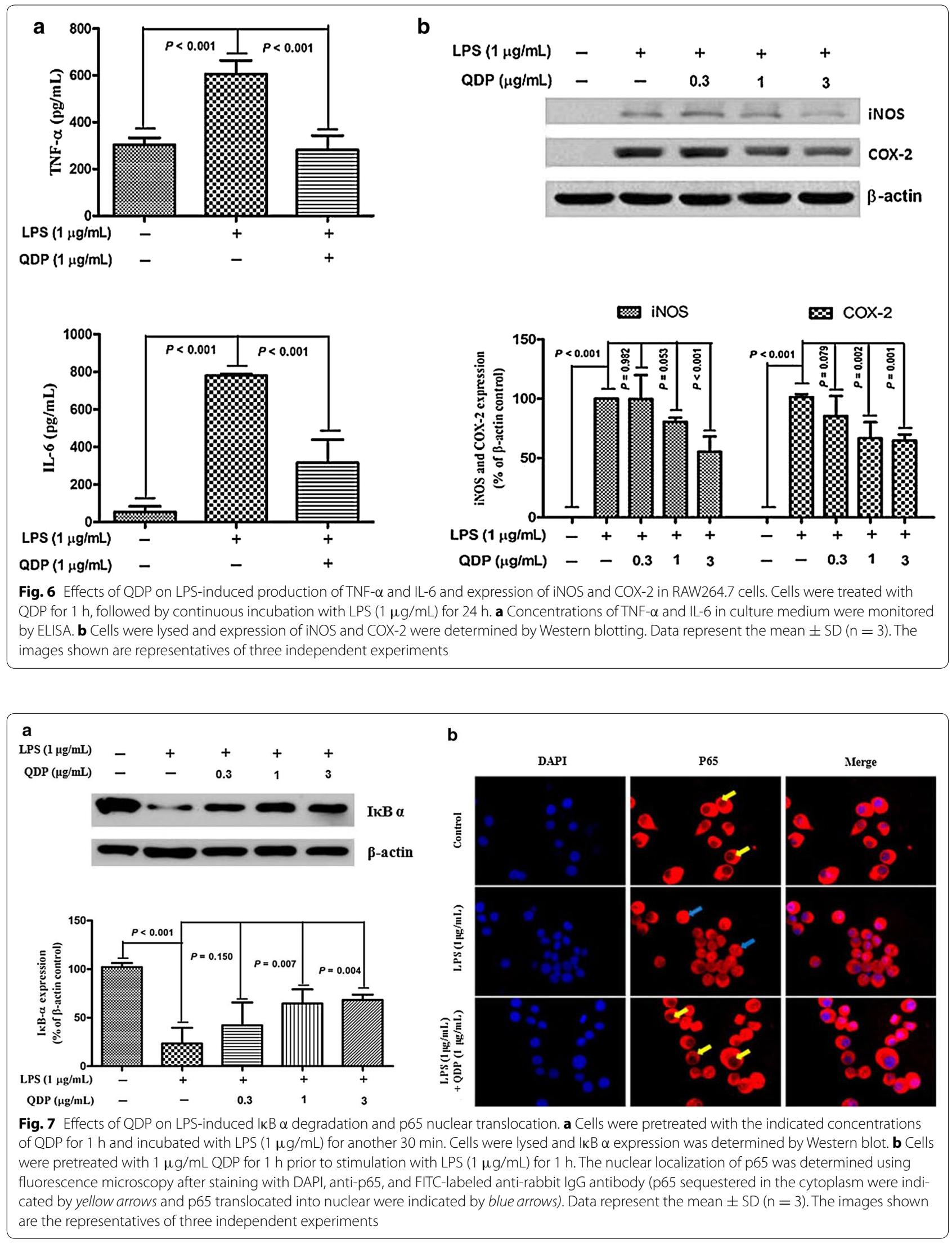


\section{Conclusion}

QDP suppressed the inflammatory responses of colonic macrophages in DSS-induced UC in mice and LPSinduced RAW264.7 cells.

\section{Abbreviations}

CMC-Na: sodium carboxymethylcellulose; COX-2: cyclooxygenase-2; DSS: dextran sulfate sodium; DAl: disease activity index; ELISA: enzyme-linked immunosorbent assay; 5-ASA: 5-aminosalicylic acid; IBD: inflammatory bowel disease; IgG: immunoglobulin G; iNOS: inducible nitric oxide synthase; IкB- $\alpha$ : inhibitor of kappa B $\alpha$; LPS: lipopolysaccharide; MPO: myeloperoxidase; NF-кB: nuclear factor kappa-light-chain-enhancer of activated B cells; PBS: phosphate buffered saline; QDP: Qing-dai powder; UC: ulcerative colitis; UPLC-QTOF-MS: ultra-performance liquid chromatography quadrupole time of flight mass spectrometry; SASP: sulfasalazine; BPI: bits per inch; IHC: immunohistochemistry.

\section{Authors' contributions}

ZXB designed and conceived the study. HTX, JP, DDH, CYL, BD and ZSL performed experiments and data analysis. HTX, SWT wrote the manuscript. QBH, $\mathrm{XJZ}$ and FPL revised the manuscript. All authors read and approved the final manuscript.

\section{Author details}

1 School of Chinese Medicine, Hong Kong Baptist University, Hong Kong, Hong Kong. ${ }^{2}$ School of Pharmacy, Guiyang Medical University, Guiyang 550004, China. ${ }^{3}$ Department of Surgery, LKS Faculty of Medicine, The University of Hong Kong, Hong Kong, Hong Kong. ${ }^{4}$ School of Chinese Medicine, Shanghai University of Chinese Medicine, Shanghai 200030, China. ${ }^{5}$ School of Fundamental Medical Science, Guangzhou University of Chinese Medicine, Guangzhou 510006, China. ${ }^{6}$ School of Chinese Medicine, Guangzhou University of Chinese Medicine, Guangzhou 510006, China.

\section{Acknowledgements}

This study was supported by research grants from the Hong Kong Baptist University (Project No. RC-IRMS/11-12/01) and the National Natural Science Foundation of China (Project No. 81560676)

\section{Compliance with ethical guidelines}

Competing interests

The authors declare that they have no competing interests.

Received: 18 September 2014 Accepted: 29 September 2015 Published online: 13 October 2015

\section{References}

1. Kaser A, Zeissig S, Blumberg RS. Inflammatory bowel disease. Annu Rev Immunol. 2010;28:573-621.

2. Chow DK, Leong RW, Tsoi KK, Ng SS, Leung WK, Wu JC, Wong WW, Chan FK, Sung JJ. Long-term follow-up of ulcerative colitis in the Chinese population. Am J Gastroenterol. 2009;104:647-54.

3. Wang YF, Ouyang Q, Hu RW. Progression of inflammatory bowel disease in China. J Dig Dise. 2010;11:76-82.

4. Macdermott RP, Green JA. Refractory ulcerative colitis treatment. Gastroenterol Hepatol (N Y). 2007;3:64-9.

5. Nanda K, Moss AC. Update on the management of ulcerative colitis: treatment and maintenance approaches focused on $\mathrm{MMX}((\mathrm{R}))$ mesalamine. Clin Pharmacol. 2012;4:41-50.

6. Inflammatory Bowel Disease Co-operation Group CSoG. Consensus on diagnosis and treatment standard of inflammatory bowel disease. Chin J Gastroenterol. 2012;12:763-81.

7. Ogata H, Matsui T, Nakamura M, lida M, Takazoe M, Suzuki Y, Hibi T. A randomised dose finding study of oral tacrolimus (FK506) therapy in refractory ulcerative colitis. Gut. 2006;55:1255-62.
8. Kaser A, Zeissig S, Blumberg RS. Inflammatory Bowel Disease. Annu Rev Immunol. 2010:28:573-621.

9. Sartor RB. Mechanisms of disease: pathogenesis of Crohn's disease and ulcerative colitis. Nat Clin Pract Gastroenterol Hepatol. 2006:3:390-407.

10. Saleh M, Trinchieri G. Innate immune mechanisms of colitis and colitisassociated colorectal cancer. Nat Rev Immunol. 2011;11:9-20.

11. Blumberg RS. Inflammation in the intestinal tract: pathogenesis and treatment. Dig Dis. 2009;27:455-64

12. Velde AAT, van Kooyk Y, Braat H, Hommes DW, Dellemijn TAM, Slors JFM, van Deventer SJH, Vyth-Dreese FA. Increased expression of $\mathrm{DC}-\mathrm{SIGN}+\mathrm{IL}-12+\mathrm{IL}-18+$ and CD83 + IL-12-IL-18-dendritic cell populations in the colonic mucosa of patients with Crohn's disease. Eur J Immunol. 2003:33:143-51.

13. Vuckovic S, Florin THJ, Khalil D, Zhang MF, Patel K, Hamilton I, Hart DNJ. CD40 and CD86 upregulation with divergent CMRF44 expression on blood dendritic cells in inflammatory bowel diseases. Am J Gastroenterol. 2001;96:2946-56.

14. Yoshino T, Nakase H, Honzawa Y, Matsumura K, Yamamoto S, Takeda $Y$, Ueno S, Uza N, Masuda S, Inui K, Chiba T. Immunosuppressive effects of tacrolimus on macrophages ameliorate experimental colitis. Inflamm Bowel Dis. 2010;16:2022-33.

15. Zigmond E, Varol C, Farache J, Elmaliah E, Satpathy AT, Friedlander G, Mack M, Shpigel N, Boneca IG, Murphy KM, et al. Ly6C(hi) monocytes in the inflamed colon give rise to proinflammatory effector cells and migratory antigen-presenting cells. Immunity. 2012;37:1076-90.

16. Steinbach EC, Plevy SE. The role of macrophages and dendritic cells in the initiation of inflammation in IBD. Inflamm Bowel Dis. 2014;20:166-75.

17. Ghia J-E, Galeazzi F, Ford DC, Hogaboam CM, Vallance BA, Collins S. Role of M-CSF-dependent macrophages in colitis is driven by the nature of the inflammatory stimulus. Am J Physiol Gastrointest Liver Physiol. 2008:294:G770-7.

18. Cheng Z, editor. Yi-Fang-Lei-Ju (reprint edition). Beijing: People's Medical Publishing House; 2006

19. Du L, Liu R. The effect of Qing-dai San in treatment of colitis: 118 cases clinical study. Liaoning J Tradit Chin Med. 1998:25:356-7.

20. Xie Z, Li H, Du L. Clinical research progress of Qingdaisan enema for ulcerative colitis treatment. China Med Her. 2013;10:31-3.

21. Zou L, Liu Y, Wu Q, Xian Y, Zhou H, Du L. Effect of Qingdaisan on ulcerative colitis in rats. J China Med Univ. 2006;35:15-6.

22. Kim JK, Park GM. Indirubin-3-monoxime exhibits anti-inflammatory properties by down-regulating NF-kappaB and JNK signaling pathways in lipopolysaccharide-treated RAW264.7 cells. Inflamm Res. 2012:61:319-25.

23. Commission CP, editor. Chinese pharmacopoeia (1990), Part I. Beijing: People's Medical Publishing House; 1991.

24. Commission CP, editor. Chinese pharmacopoeia (2010), Part I. Beijing: Chemical Industry Publisher; 2011.

25. You SX, Liu SJ, Wu KD, Liu SH, Lin RC. The comparative study on FTIR fingerprint for alum and calcined alum. Chin J Pham Anal. 2011:31:1054-8.

26. Wirtz S, Neufert C, Weigmann B, Neurath MF. Chemically induced mouse models of intestinal inflammation. Nat Protoc. 2007;2:541-6.

27. Kim JM, Kang HW, Cha MY, Yoo D, Kim N, Kim IK, Ku J, Kim S, Ma SH, Jung HC, et al. Novel guggulsterone derivative GG-52 inhibits NF-kappaB signaling in intestinal epithelial cells and attenuates acute murine colitis. Lab Invest. 2010;90:1004-15.

28. Xiao HT, Lin C, Ho DHH, Peng J, Chen Y, Tsang SW, Wong M, Zhang $X J$, Zhang M, Bian ZX. Inhibitory effect of the gallotannin corilagin on dextran sulfate sodium-induced murine ulcerative colitis. J Nat Prod. 2013;76:2120-5

29. Chen X, Wu X, Zhou Q, Howard OM, Netea MG, Jj O. TNFR2 is critical for the stabilization of the CD4 + Foxp3 + regulatory $T$. cell phenotype in the inflammatory environment. J Immunol. 2013;190:1076-84.

30. Weigmann B, Tubbe I, Seidel D, Nicolaev A, Becker C, Neurath MF. Isolation and subsequent analysis of murine lamina propria mononuclear cells from colonic tissue. Nat Protoc. 2007:2:2307-11.

31. Fan $H$, Qi D, Yang M, Fang H, Liu K, Zhao F. In vitro and in vivo anti-inflammatory effects of 4-methoxy-5-hydroxycanthin-6-one, a natural alkaloid from Picrasma quassioides. Phytomedicine. 2013;20:319-23.

32. Adamec J, Jannasch A, Huang J, Hohman E, Fleet JC, Peacock M, Ferruzzi MG, Martin B, Weaver CM. Development and optimization of an LC-MS/ MS-based method for simultaneous quantification of vitamin D2, 
vitamin D3, 25-hydroxyvitamin D2 and 25-hydroxyvitamin D3. J Sep Sci. 2011;34:11-20.

33. Debnath T, Kim DH, Lim BO. Natural products as a source of anti-inflammatory agents associated with inflammatory bowel disease. Molecules. 2013;18:7253-70.

34. Moodley K, Mackraj I, Naidoo Y. Cardiovascular effects of Tulbaghia violacea Harv. (Alliaceae) root methanolic extract in Dahl salt-sensitive (DSS) rats. J Ethnopharmacol. 2013;146:225-31.
35. Bain CC, Scott CL, Uronen-Hansson H, Gudjonsson S, Jansson O, Grip O, Guilliams M, Malissen B, Agace WW, Mowat AM. Resident and pro-inflammatory macrophages in the colon represent alternative context-dependent fates of the same Ly6Chi monocyte precursors. Mucosal Immunol. 2013;6:498-510

36. Lim WC, Hanauer SB. Controversies with aminosalicylates in inflammatory bowel disease. Rev Gastroenterol Disord. 2004;4:104-17.
Submit your next manuscript to BioMed Central and take full advantage of:

- Convenient online submission

- Thorough peer review

- No space constraints or color figure charges

- Immediate publication on acceptance

- Inclusion in PubMed, CAS, Scopus and Google Scholar

- Research which is freely available for redistribution

Submit your manuscript at www.biomedcentral.com/submit 